\title{
COTAS RACIAIS EM CONCURSOS PÚBLICOS: UMA FORMA CONCRETIZAÇÃOO DA CIDADANIA OU DE DISCRIMINAÇÃO REVERSA?
}

\author{
Daniela Arguilar Camargo* \\ Marli Marlene Moraes da Costa**
}

SUMÁRIO: Notas introdutórias; 2 Ações afirmativas: aspectos relevantes; 3 Cotas raciais em concursos públicos: análise da decisão de constitucionalidade da lei 12.990 de 2014; 4 Afirmando a cidadania por meio das cotas raciais ou por uma discriminação reversa?; 5 Conclusão; Referências.

RESUMO: O concurso público é a forma de brasileiros e estrangeiros acessar os cargos públicos da administração pública direta e indireta. A lei federal 12.990 de 2014 estabelece a reserva de $20 \%$ das vagas para negros em concursos públicos federais. Por meio do método dedutivo e bibliográfico, o estudo parte compreensão das ações afirmativas, para posteriormente analisar a decisão de constitucionalidade da lei, e ao final verificar se por meio de sua utilização estará se afirmando a cidadania ou recaindo em uma discriminação reversa, sendo esta a finalidade do estudo. Podese concluir que, por mais que se tenham discussões contrárias e favoráveis às cotas, ao fundo consistem em um exercício de cidadania, no que se refere à união de forças críticas para que os direitos sejam garantidos e viabilizados. Contudo, não vem a corrigir a desigualdade racial, pois parte da população negra permanece distante das oportunidades de aperfeiçoar a sua condição social.

PALAVRAS-CHAVE: Cidadania; Cotas raciais; Concursos públicos; Desigualdade racial.

\section{RACIAL QUOTAS IN PUBLIC COMPETITIONS: A FORM CONCRETIZATION OF CITIZENSHIP OR CAUSING A REVERSAL DISCRIMINATION?}

ABSTRACT: The public tender is the way for Brazilians and foreigners to access the public positions of the direct and indirect public administration. Federal Law 12,990 establishes the reserve of $20 \%$ of vacancies for blacks in federal public tenders.

\footnotetext{
Mestre em Direitos Sociais e Políticas Públicas pelo Programa de Pós-graduação em Direito da Universidade de Santa Cruz do Sul, Brasil. E-mail: danielacamargo68@gmail.com

${ }^{* *}$ Doutora em Direito pela Universidade Federal de Santa Catarina (UFSC). Docente da Graduação e da PósGraduação Lato Sensu em Direito da Universidade de Santa Cruz do Sul (UNISC). Docente e Coordenadora do Programa de Pós-Graduação em Direito - Mestrado e Doutorado da UNISC. Coordenadora do Grupo de Estudos Direito, Cidadania e Políticas Públicas do PPGD da UNISC, Brasil.
} 
Through the deductive and bibliographic method, the study starts understanding affirmative actions, to later analyze the constitutionality decision of Law 12.990, and finally to verify if through its use it is affirming citizenship or falling into a reverse discrimination, this being the purpose of the study. It can be concluded that, even if there are opposing and favorable discussions, the quotas consist of a citizenship exercise, as regards the union of critical forces so that the rights are guaranteed and made feasible. However, it does not correct racial inequality, since part of the black population remains distant from opportunities to improve its social status.

KEY WORDS: Citizenship; Racial quotas; Public Contests; Racial inequality.

\section{COTAS RACIALES EN CONCURSOS PÚBLICOS: UNA FORMA CONCRETIZACIÓN DE LA CIUDADANÍA O CAUSADORA DE UNA DISCRIMINACIÓN REVERSA?}

RESUMEN: El concurso público es la forma de brasileños y extranjeros acceder a los cargos públicos de la administración pública directa e indirecta. La Ley federal 12.990 establece la reserva del 20\% de las vacantes para negros en concursos públicos federales. A través del método deductivo y bibliográfico, el estudio parte comprensión de las acciones afirmativas, para posteriormente analizar la decisión de constitucionalidad de la Ley 12.990, y al final verificar si por medio de su utilización se estará afirmando la ciudadanía o recayendo en una discriminación reversa, siendo ésta la finalidad del estudio. Se puede concluir que, por más que se tengan discusiones contrarias y favorables las cuotas, al fondo consisten en un ejercicio de ciudadanía, en lo que se refiere a la unión de fuerzas críticas para que los derechos sean garantizados y viabilizados. Sin embargo, no viene a corregir la desigualdad racial, pues parte de la población negra permanece distante de las oportunidades de perfeccionar su condición social.

PALABRAS CLAVE: Ciudadanía; Cotas raciales; Concursos públicos; Desigualdad racial.

\section{NOTAS INTRODUTÓRIAS}

No Brasil a desigualdade social está associada à desigualdade racial, considerando a realidade inaceitável dentro de uma sociedade que tem como finalidade a erradicação da pobreza, a redução de desigualdades e promoção do bem comum. Embora os movimentos sociais negros vêm há muito tempo denunciando essas 
constatações, apenas recentemente instalou-se e intensificou-se os instrumentos e políticas na busca da promoção da igualdade racial. Assim como a atuação de setores capazes de modificar essas situações, com a implementação de políticas que venham a concretizar direitos, despertando interesses de desenvolvimento do estudo referente aos meios de transformação social.

Esse interesse fundamenta-se no momento em que é possível visualizar na educação a justificativa para a igualdade e cidadania. Diante disso, e observando que o Estado liberal concedeu lugar para o Estado social, ancorado no neoconstitucionalismo - cujo projeto é a concretização de políticas públicas como maneira de combate às desigualdades - não restam dúvidas de que as ações afirmativas são consideradas como um meio de efetivação dos direitos sociais. Entendidas como um instrumento que busca concretizar a igualdade material, com preferência aos segmentos sociais marginalizados quando se tratam de acesso a direitos.

Por conseguinte, vislumbrando a lei de reserva de cotas para negros em concursos públicos federais $\mathrm{n}^{\circ} 12.990$, observa-se que a maneira de acessar os cargos públicos é por meio dos concursos, em que brasileiros e estrangeiros possuem o direito de prestar, consoante ao artigo 37 da Constituição Federal. A realização se dá em virtude da permissão de maior número de pessoas poderem se candidatar as vagas disponibilizadas. Em referência à lei mencionada, 20\% daquelas são reservadas aos candidatos negros. Trata-se de uma ação afirmativa que objetiva a redução da desigualdade racial e as suas consequências relacionadas ao serviço público brasileiro.

O Instituto Brasileiro de Geografia e Estatística apontou que, em 2010, apenas $30 \%$ dos servidores eram negros e pardos. Nesse estudo, serão verificadas a justificativa da Lei apresentada pela Câmara de Deputados, de autoria do chefe de gabinete da Câmara e da ministra-chefe da Secretaria de Políticas de Promoção da Igualdade Racial, e a decisão de constitucionalidade da lei declarada pelo Superior Tribunal de Justiça, em Ação declaratória de Constitucionalidade proposta pela Organização dos Advogados do Brasil (OAB). E diante desses dois fatores, surge a problemática da pesquisa: com a lei de reserva de vagas para negros em concursos públicos estará se afirmando a cidadania ou recaindo-se em uma discriminação reversa?

Para responder a esse questionamento, utilizou-se o método dedutivo, pois a conclusão já está, de certa forma, implícita no decorrer do texto, e o bibliográfico, observando-se várias obras e índices. A estrutura parte da compreensão das ações afirmativas no país, em um sentido geral, para posteriormente analisar a justificativa 
da lei apresentada pela Câmara de Deputados, e a decisão de constitucionalidade da lei 12.990 de 2014 proferida pelo Supremo Tribunal Federal, verificando ao final, se com a referida lei estará se afirmando a cidadania ou recaindo-se em uma discriminação reversa.

Pode-se concluir que, por mais que se tenham discussões favoráveis ou contrárias, ao fundo consistem em um exercício de cidadania, no que se refere à união de forças críticas para que os direitos sejam garantidos e viabilizados. Contudo, isso não vem a corrigir a desigualdade racial, tendo em vista que parte da população negra permanece distante das oportunidades de aperfeiçoar as suas condições sociais.

\section{AÇÕES AFIRMATIVAS: ASPECTOS RELEVANTES}

A expressão foi criada pelo então presidente dos Estados Unidos, J. F. Kennedy, em 1963, representando "ação afirmativa" "um conjunto de políticas públicas e privadas de caráter compulsório, facultativo ou voluntário, concebidas com vistas ao combate da discriminação de raça, gênero etc., bem como para corrigir os efeitos presentes da discriminação praticada no passado"03. Surgidas em um contexto global, foram conquistadas pelo movimento negro, após décadas de lutas pelos direitos civis.

Após a declaração dos direitos humanos, em 1948, a nova representação do homem é constituída com ideias, tendo em vista que os direitos são extensivos a todos aqueles que compõem a sociedade, independentemente de suas condições, homens e mulheres, brancos e negros, são considerados iguais. Ainda "aquilo que foi motivo de discriminação e até condenações agora passa a ser aceito e considerado como pressuposto de que as diferenças são respeitadas", e segue abordando que "pensar nas diferenças entre grupos sociais, entre excluídos e incluídos constitui-se numa tarefa árdua para os grupos que governam os Estados [...]"04.

O marco decisivo no processo estadunidense, anteriormente a menção de ações afirmativas, foi a decisão no caso Brown versus Board of Education of Topeka, no ano de 1954, em que se declarou inconstitucional a discriminação pela cor nas escolas públicas dos EUA, assinalando-se "início de um novo período nas relações

${ }^{03}$ GOMES, Joaquim Barbosa. Ação afirmativa e princípio constitucional da igualdade: o direito como instrumento de transformação social. Rio de Janeiro: Renovar, 2001. p. 17.

${ }^{04}$ BEDIN, Gilmar Antônio. Cidadania, direitos humanos e equidade. Ijuí: Unijuí, 2012. p. 10. 
entre a União e os Estados, sobretudo os do Sul, no campo dos direitos civis", a partir do que "toda a estrutura legal segregacionista criada depois da Reconstrução para tirar dos negros o poder político, mantê-los iletrados e economicamente subjugados, irá ser paulatinamente destruída" ${ }^{05}$.

Os objetivos dessas ações estão na indução de transformações de ordem cultural, psicológica e pedagógica, a fim de retirar do imaginário coletivo a ideia de supremacia racial contra a subordinação racial ou de gênero. Além disso, coibir a discriminação e eliminar os efeitos dessa, com a implantação da diversidade e ampliação da representatividade desses grupos minoritários nos diversos setores, seriam outros objetivos a serem concretizados por meio das ações afirmativas ${ }^{06}$.

Mesmo que a "ação afirmativa" seja associada à experiência dos EUA, no Estado brasileiro é vista como uma benesse que é aplicada aos negros e reduzida a política de cotas, com a ideia de dispensar um tratamento diferenciado a determinados grupos com relação à função da discriminação. Um exemplo é a Lei dos Dois Terços, implementada no ano de 1930, que, adveio para garantir a participação majoritária dos trabalhadores em empresas que estavam funcionando no Brasil, na época em que muitas delas eram de propriedades de estrangeiros e que discriminavam os nativos ${ }^{07}$.

A Constituição Federal de 1988 traz em seu preâmbulo a instituição de um Estado democrático que assegure o exercício de direitos, liberdade, igualdade entre outros, sem preconceitos. O seu artigo $1^{\circ}$ dispõe sobre os fundamentos da República, quais sejam, cidadania, dignidade da pessoa humana etc. E em seguida vem o artigo $3^{\circ}$, que nada mais é do que o agasalho da ação afirmativa, elucidando o meio de corrigir as desigualdades, com o peso da lei, sua imperatividade a favor daquele que é discriminado. Um dos preceitos constitucionais é o desenvolvimento nacional, que preza por uma posição ativa, com a erradicação da pobreza, marginalização e redução das desigualdades.

No artigo $5^{\circ}$ do referido ordenamento, está o princípio da igualdade, pelo qual se afirma que todos são iguais perante a lei, sem distinção, devendo esta leitura ser realizada com base nos fundamentos e objetivos da República, ainda que deva se valer das ações afirmativas para que isso seja concretizado. Nesse sentido,

\footnotetext{
${ }^{05}$ RODRIGUES, Fernando. Racismo cordial. In. TURRA, C.; VENTURI, G. (Org.). Racismo cordial: a mais completa análise sobre preconceito de cor no Brasil. São Paulo: Folha de São Paulo / Datafolha, 1998. p. 170.

${ }^{06}$ GOMES, Joaquim Barbosa. Ação afirmativa e princípio constitucional da igualdade: o direito como instrumento de transformação social. Rio de Janeiro: Renovar, 2001.

${ }^{07}$ CARVALHO, José Murilo de. Cidadania no Brasil: o longo caminho. Rio de Janeiro: Civilização brasileira, 2016.
} 
estas se constituem um remédio eficaz para os males (desigualdades raciais), sendo indispensáveis para ampla conscientização da sociedade e lideranças políticas, que tenham maior expressão referente à necessidade de eliminação da redução das desigualdades sociais.

Nesse sentido, a representação de um homem livre, igual a todos os outros, contempla as dimensões de vivência na sociedade, tanto em sua vida em família como na vida associativa, diferentes as formas de organização social. Ainda, "desse modo a inserção social do homem é um pressuposto que garante a sua plenitude, ele somente seria completo com o respeito a sua integridade como pessoa humana" 08 .

Ainda, demorou para que o direito constitucional começasse a discutir as questões da sociedade. O início foi com a decisão do Supremo Tribunal Federal, quando este debateu sobre o crime de racismo. Outro grande acontecimento foram as medidas compensatórias, relativas às ações afirmativas, destinadas à promoção e implementação da igualdade material; uma ferramenta jurídica que tem aplicação em prol dos negros.

Destaca-se, ainda, que a partir dos anos 90 intensificou-se fortemente a adoção das cotas em exames de vestibular de algumas universidades públicas brasileiras, destinadas para o acesso de negros e alunos carentes ao nível superior da educação. Ainda, Cármen Lúcia Antunes identifica as ações como uma tentativa de concretizar o princípio da igualdade, Cármen Lúcia Antunes Rocha.

A definição jurídica objetiva e racional da desigualdade dos desiguais, histórica e culturalmente discriminados, é concebida como uma forma para se promover a igualdade daqueles que foram e são marginalizados por preconceitos encravados na cultura dominante na sociedade. Por esta desigualação positiva promove-se a igualação jurídica efetiva: por ela afirma-se uma fórmula jurídica para se provocar uma efetiva igualação social, política, econômica no e segundo o Direito, tal como assegurado formal e materialmente no sistema constitucional democrático. A ação afirmativa é, então, uma forma jurídica para se superar o isolamento ou a diminuição social a que se acham sujeitas as minorias ${ }^{09}$.

Diante desse entendimento, as ações afirmativas têm a objetividade de implementação da igualdade concreta no plano fático, em que a isonomia não consegue proporcionar de forma plena. Entre as ações afirmativas que estão sendo ex-

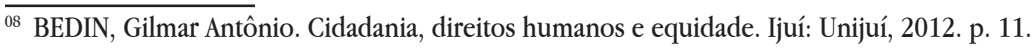

${ }^{09}$ ROCHA, Cármen Lúcia Antunes. Ação afirmativa - O conteúdo democrático do princípio da igualdade jurídica. São Paulo: Revista Trimestral de Direito Público $n^{0}$ vol. 15 nº. 85, mar. 1996. p. 85. 
perimentadas, aquela que gera mais polêmica é o programa de cotas para pessoas negras, que constituem uma forma extrema de ação afirmativa, ou seja, a reserva de um percentual destinando vagas para um grupo específico, principalmente quando se trata de acesso à universidade, mercado de trabalho.

Por serem consideradas, as ações afirmativas, como uma solução de um enfrentamento político e social em âmbito global, não estão limitadas ao direito interno, envolvendo também o direito internacional. O Brasil assumiu o compromisso de agir contra a discriminação racial, perante a comunidade internacional, aprovada pelo decreto $\mathrm{n}^{\circ} 23$ em 1967, a Conversão Internacional sobre a Eliminação de todas as formas de Discriminação Racial, ora ratificada em 1968, vigorando com a edição do decreto 65.810, em 1969.

Essa convenção determina que os entes da federação devem proceder com a eliminação da discriminação, inclusive por meio de medidas legislativas e fortalecimento das organizações que tenham capacidade para eliminar barreiras entre as raças, destacando ainda a necessidade de um prazo para executar medidas para que não haja qualquer tipo discriminatório.

Ainda, foi aprovado, em 2010, o Estatuto da Igualdade Racial, com a finalidade de garantir a população negra, a efetividade da igualdade de oportunidades, com a defesa dos direitos individuais, difusos e coletivos, bem como o combate da discriminação e demais formas de intolerância. Define os programas de ações afirmativas no artigo $4^{\circ}$ parágrafo único, em que estes deverão se constituir em políticas públicas destinadas à reparação das distorções e desigualdades sociais, bem como as demais práticas discriminatórias, ocasionadas nas esferas pública e provada, durante o processo de formação social do Brasil.

Nesse sentido, entende João Pedro Schmidt ${ }^{10}$ que quando o Estado apoia e fortalece as iniciativas da sociedade, assim como os movimentos (também em prol das ações afirmativas), para com as políticas públicas, este fortalece o senso de cidadania, e também estimula o capital social, inibindo aquela tradição autoritária da política no Brasil.

Atualmente, a população que se declara negra no Brasil, conforme os dados do Instituto Brasileiro de Geografia e Estatística (IBGE), em 2010, representam 7,52\% do total da população, somando-se a população parda, tem-se 50,94\%. Em 2014, ainda de acordo com o IBGE, representam 53,6\%, entre pretos e partos, e os

\footnotetext{
${ }^{10}$ SCHMIDT, João Pedro. O caráter público não-estatal da universidade comunitária: aspectos conceituais e
} jurídicos. Revista do Direito, Santa Cruz do Sul, p. 44-66, jan. 2008. 
brasileiros que se declaravam brancos, estão em torno de $45,5 \%$.

Tabela 1. Opção de cor/raça ou etnia no período de 1872-2015

\begin{tabular}{lllllllllllll}
\hline OPCAO & 1872 & 1890 & 1940 & 1950 & 1960 & 1980 & 1991 & 2000 & 2010 & 2012 & 2014 & 2015 \\
\hline $\begin{array}{l}\text { Branca } \\
3\end{array}$ & 38,1 & 44 & 63,5 & 61,7 & 61,09 & 54,23 & 51,56 & 53,74 & 47,51 & 46,3 & 45,5 & 45,2 \\
$\begin{array}{l}\text { Preta ou } \\
\text { parda }\end{array}$ & 58 & 47 & 35,8 & 37,5 & 38,15 & 44,8 & 47,45 & 44,66 & 50,94 & 52,9 & 53,6 & 53,9 \\
\hline
\end{tabular}

Fonte: Instituto Brasileiro de Geografia e Estatística - IBGE.

Tendo em vista a inserção dos negros no mercado de trabalho, dados que serão vistos posteriormente, as ações afirmativas nada mais são do que políticas públicas feitas pelo governo, ou iniciativa privada com o intuito de corrigir as desigualdades raciais acumuladas ao longo dos anos. Buscam oferecer a igualdade e oportunidade para todos. Podendo ser de três tipos, ou seja, aquelas que têm o condão de reverter a representação negativa dos negros; promoção da igualdade de oportunidades; combate ao racismo e preconceito.

Com relação às oportunidades sociais são evidenciadas por Amartya Sen, como "as disposições que a sociedade estabelece nas áreas da educação, saúde etc., as quais influenciam a liberdade substantiva de o indivíduo viver melhor"11. Nesse sentido, entende que as facilidades são importantes para a condução da vida privada e para a participação mais efetiva em atividades econômicas e políticas, citando, como exemplo, o analfabetismo, que pode ser grande barreira na participação de tais atividades. A taxa de analfabetismo entre pretos e brancos é de 22,3\% para 5\% dos brancos, de acordo com o IBGE, dados de 2016.

Um importante órgão que atua junto com a União e demais entes federados é a Seppir (Secretaria nacional de políticas de promoção da igualdade racial) ${ }^{12}$, colaborando com a elaboração, acompanhamento e execução das ações afirmativas nas áreas como juventude, mulheres, educação, trabalho. No ano de 2012, o STF decidiu que estas ações afirmativas são constitucionais e essenciais para a redução e eliminação das desigualdades e discriminações. Assim, uma ação não deve ser observada como injusta, ou como um benefício, pois ela só é criada quando são percebidos históricos de injustiças e diretos que não foram assegurados, de acordo com a Seppir.

${ }^{11}$ SEN, Amartya. Desenvolvimento como liberdade. São Paulo: Cia das Letras, 2000. p. 56.

${ }^{12}$ SEPPIR. Secretaria de Políticas de Promoção da Igualdade Racial. 2013. Disponível em: < http://www.seppir. gov.br/ >. Acesso em: 06 de jul. 2017 
Dessa forma, as ações afirmativas vêm para integrar o combate da herança de escravidão, segregação social e racismo. E para que se compreenda a necessidade de uma ação afirmativa, necessário entender o contexto social do país. Assim, passa-se a análise da ação afirmativa, a reserva de $20 \%$ das vagas disponibilizadas por concursos públicos federais para negros, tanto da justificativa da apresentação do projeto de lei em 2013, quanto da decisão que reconheceu a constitucionalidade, após a conversão em lei $\mathrm{n}^{\mathrm{O}} 12.990$ de 2014 , proferida pelo STF.

\section{COTAS RACIAIS EM CONCURSOS PÚBLICOS: ANÁLISE DA DECISÃO DE CONSTITUCIONALIDADE DA LEI 12.990 DE 2014.}

Inicialmente, e de forma diacrônica, em 2013 foi apresentado pela Câmara de Deputados, um projeto de lei $\mathrm{n}^{\mathrm{0}} 6.738$, com a proposta de reserva de vagas em concursos públicos, para negros. Ainda nesse ano, durante uma sessão de abertura da III Conferência Nacional de Promoção da Igualdade Racial, a então presidente Dilma Rousseff comunicou que enviou ao congresso nacional, o referido projeto. Enfatizando que se tratava de uma pauta histórica no movimento negro. O projeto possui seis objetivos, quais sejam a reserva de $20 \%$ das vagas em concursos públicos, quando forem superiores ou iguais a três.

Dispõe ainda sobre os critérios de arredondamento; da especificação em editais da reserva dos cargos; os beneficiários da reserva, com a declaração de pretos ou pardos no ato da inscrição, conforme o quesito utilizado pelo IBGE; a determinação de que estes concorrerão, concomitantemente, às listas de vagas reservadas e de ampla concorrência, que de acordo com a sua classificação, e para que tenha efeito o preenchimento da vaga, tem a prioridade a sua aprovação na lista de ampla concorrência, liberando a vaga de reserva.

E ainda, em caso de um candidato negro desistir, o próximo negro irá ser classificado; define que na ausência de certo número de candidatos negros aprovados nas vagas reservadas, estas se reverterão em ampla concorrência. Os últimos dois correspondem à responsabilidade de uma avaliação anual do sistema de reserva das vagas; e a estipulação da vigência da norma, que inicia com a sua publicação e termina com dez anos, conforme PL n ${ }^{\circ}$ 6.738.

A justificativa para o projeto referenciou a constatação, por meio de estudos, as diferenças dos indicadores sociais das populações branca e negra, e que 
mesmo com um esforço de redução da desigualdade e expansão do emprego, bem como com a proteção social, com a vinda do Estatuto da Igualdade Racial, os índices não alteraram de forma significativa. Aplicando a realidade na composição racial dos servidores da administração pública, sendo constatada uma discrepância entre os porcentuais da população negra no país e aquela de servidores públicos.

A análise dos dados, trazidos pela justificativa, demonstra que a população negra representava 50,74\% em 2013, no poder executivo federal essa representação é de $30 \%$, considerando que destes, $82 \%$ dos servidores possuem a informação de cor ou raça no sistema. Evidenciou-se que nos concursos constituem um método de seleção isonômico e transparente, sendo que a sua utilização não tem sido tão suficiente para garantir um tratamento isonômico entre as raças, tendo falha ao fomentar o resgate da dívida histórica do país com a população negra.

Diante desse fato, apresenta a justificativa que para que esse enfrentamento seja solucionado, é necessário que se adote uma política afirmativa com prazo de dez anos, e que venha aproximar a composição de servidores da administração pública federal com os índices da população brasileira.

Aponta ainda que diversas ações fomentadas pelo Estatuto (como as reservas de vagas nas universidades) impactam no ingresso dos negros por meio da ampla concorrência, constituindo a reserva de vaga proposta com avanço de grande importância para a efetivação da igualdade entre as raças, a fim de garantir que os quadros do executivo federal venham a refletir de forma realista da diversidade existente no Brasil. Nesse sentido, a justificativa considera o papel da administração pública na formulação e implementação de políticas para todos os segmentos da população, elevando o potencial incentivador de adoção de ações semelhantes no setor público e provado, cumprindo com a lei 12.288 de 2010, artigo $39^{13}$.

A fundamentação do prazo de dez anos para a ação afirmativa, que tem a efetividade de garantir a sua temporalidade, e pela dificuldade de quantificar o impacto das outras ações sobre o ingresso dos negros no serviço público pela ampla concorrência, considerou-se de grande importância a avaliação do alcance em médio prazo, assim como do exame em períodos pelo órgão responsável, do que trata a

\footnotetext{
${ }^{13}$ Art. 39. O poder público promoverá ações que assegurem a igualdade de oportunidades no mercado de trabalho para a população negra, inclusive mediante a implementação de medidas visando à promoção da igualdade nas contratações do setor público e o incentivo à adoção de medidas similares nas empresas e organizações privadas.
} 
referida lei, artigo $49 \$ 1^{014}$. Dessa forma, foi sugerido o projeto de lei, para assegurar no período de dez anos esses $20 \%$ das vagas reservadas aos negros em concursos públicos para cargos na administração direta e indireta do executivo federal.

A observância deve constar em edital, para que se faça jus ao direito, sendo que o candidato deve se autodeclarar negro, de acordo com o quesito de cor ou raça do IBGE. Dessa maneira, aqueles negros aprovados no quadro quantitativo das vagas de ampla concorrência não ocuparão uma vaga reservada, possibilitando a real superação da situação atual. Ao final do prazo da lei, deverá ser feita uma avaliação de resultados, o que virá a possibilitar uma nova ação afirmativa, ou não.

Com a aprovação do projeto de lei na Câmara de Deputados, e a sua transformação em lei ordinária $\mathrm{n}^{0} 12.990$ de 2014, sugiram as controvérsias por parte de diversos segmentos da sociedade, sendo que em 2016 a OAB protocola uma ação buscando a declaração de constitucionalidade da referida lei. Recebida pelo Ministro Luís Roberto Barroso, este entendeu previamente que a ação seja analisada pela Corte diretamente quanto ao seu mérito, sem pedido liminar, enfatizando que a matéria ora submetida é de inequívoca relevância, possuindo um significado para a segurança jurídica. A ação passa a envolver uma análise da compatibilidade da ação afirmativa para negros, observando o princípio da igualdade e proporcionalidade.

Conforme a justificativa para a proposição da ação por parte da OAB, entende-se que, quando se trata de garantir a isonomia no serviço público, diversas questões exigem do STF um posicionamento, como no caso da lei 12.990 de 2014, para reprimir aquelas posturas divergentes, referente ao procedimento de autodeclaração. Nesse mesmo sentido, a posição nas demais instâncias do Judiciário não é uniforme, tendo decisões que declaram a inconstitucionalidade da norma e pedidos de suspensão tendo em vista a aplicação da norma.

As declarações de inconstitucionalidade da Lei de Cotas por outras instâncias contrariam a decisão do STF na ADPF 186, que passou a considerar constitucional aquela política de cotas étnico-raciais para os processos seletivos na Universidade de Brasília. Destaca ainda, a OAB, em sede de petição inicial, que a proposição dessa lei tem como finalidade a criação de ações afirmativas de combate às desigualdades raciais, para buscar maior representação da população negra e parda nos serviços

\footnotetext{
${ }^{14}$ Art. 49. O Poder Executivo federal elaborará plano nacional de promoção da igualdade racial contendo as metas, princípios e diretrizes para a implementação da Política Nacional de Promoção da Igualdade Racial (PNPIR). § 1o A elaboração, implementação, coordenação, avaliação e acompanhamento da PNPIR, bem como a organização, articulaçã̃o e coordenação do Sinapir, serão efetivados pelo órgão responsável pela política de promoção da igualdade étnica em âmbito nacional.
} 
públicos federais.

Essa discriminação não vem a ocorrer somente no campo da educação, mas também no trabalho, em que o processo de inclusão permeia pela ampliação das oportunidades ora oferecidas pelo Estado, mercado de trabalho e escola. Observou-se, ainda, que as cotas no serviço público representam a extensão daquelas universitárias, configurando então a evolução das ações afirmativas no combate da desigualdade racial e do racismo.

Em caráter liminar, a OAB buscou a suspensão daquelas decisões judiciais que entendem inconstitucional o referido ordenamento, até que fosse julgada a ADC 41 (Ação declaratória de constitucionalidade da lei 12.990). Argumentando, a $\mathrm{OAB}$, que a insegurança jurídica vem a atingir os candidatos cotistas e a administração pública, requerendo, então, a declaração de constitucionalidade da lei. Sustentando ao final que a oportunidade e igualdade ora ofertada para um indivíduo por meio de políticas voltadas ao combate da discriminação racial, além de possuir efeito imediato sobre os destinatários, detém papel importantíssimo na configuração da modalidade em longo prazo.

$\mathrm{Na}$ decisão proferida pelo STF, em 08 de junho de 2017, concluiu-se a validade da lei 12.990 de 2014, reservando $20 \%$ das vagas oferecidas em concursos públicos aos negros. O julgamento teve como marco inicial o mês de maio do ano corrente, em que Barroso votou pela constitucionalidade, considerando a motivação da lei por parte de um dever de reparação histórica de escravidão e racismo estrutural frente à sociedade. Esse voto foi acompanhado pelos ministros Alexandre de Moraes, Edson Fachin, Rosa Weber e Luiz Fux. Por conseguinte, o ministro Toffoli lembrou que quando era advogado geral da União, já havia se manifestado pela compatibilidade das ações afirmativas, referenciando o princípio da igualdade.

Para esse ministro, muito mais que sua compatibilidade com a Constituição Federal, trata-se de uma exigência, tendo em vista o princípio da isonomia. Possuindo ainda a sintonia com a jurisprudência do STF, que já confirmou a constitucionalidade da reserva de vagas para os portadores de deficiência e o sistema de cotas no acesso ao ensino superior. Explicou, ainda, que, por meio do seu voto, restringem-se os efeitos dessa decisão para os cargos de provimento em concurso público, nos órgãos da administração direta e indireta, no que tange a União, não tendo extensão para os demais entes federados. Segue parte do julgamento da Ação. 
É constitucional a reserva de $20 \%$ das vagas oferecidas nos concursos públicos para provimento de cargos efetivos e empregos públicos no âmbito da administração pública direta e indireta. É legítima a utilização, além da autodeclaração, de critérios subsidiários de heteroidentificação, desde que respeitada a dignidade da pessoa humana e garantidos o contraditório e a ampla defesa.

Dessa maneira, com a decisão, defenderam-se as liberdades e os direitos da população negra, reconhecendo-se por meio da Constituição o dever de atribuir para todos os que se situam na margem do sistema de conquista no Brasil, aquela condição que vem a ser essencial para os titulares de direito, de receberem o reconhecimento como pessoas dotadas de dignidade e de respeito social. Trata-se, assim, de uma ação afirmativa, e muito mais que uma lei, é necessário adotar medidas objetivas, tanto de curso em longo prazo, pois as mudanças ideológicas, ideias e critérios não são fáceis de transformar.

Mesmo que se tenham passados séculos, as tradições e os preconceitos não se extinguem por meio de uma lei, e aqui se ressalta a educação como um meio para a luta. Para que a educação seja efetiva, será necessário a retroalimentação e a estimulação na luta contra os preconceitos raciais. Dessa análise, passa-se a verificar se com essa lei, estará se afirmando a cidadania ou estará se realizando uma discriminação reversa.

\section{AFIRMANDO A CIDADANIA POR MEIO DAS COTAS RACIAIS OU POR UMA DISCRIMINAÇÃO REVERSA?}

Considerando inicialmente que se passaram muitos anos desde a Abolição da Escravatura, observa-se, a partir de agora, como a população negra brasileira exerce a sua cidadania com igualdade em relação à população branca. Conforme enfatiza Thomas Humphrey Marshall "a cidadania é um status concedido aqueles que são membros integrais de uma comunidade" ${ }^{15}$. A questão da cidadania é abordada por Vieira Liszt, como a participação ativa do cidadão, dentro do Estado, com direitos e obrigações.

Distinguindo a noção de cidadania e sociedade civil, sendo que a primeira é reforçada pelo Estado e a segunda abrange grupos e pressiona determinações po-

\footnotetext{
${ }^{15}$ MARSHALL, Thomas Humphrey. Cidadania, classe social e status. Rio de Janeiro: Zahar, 1967. p. 85.
} 
líticas, produzindo estruturas que favorece a cidadania. E segue complementando que "a sociedade civil cria grupos e pressiona em direção a determinadas opções políticas, produzindo, consequentemente, estruturas institucionais que favorecem a cidadania" ${ }^{\prime 16}$.

Percebe-se, conforme elucidam Marli Marlene Moraes da Costa e Suzete da Silva Reis ${ }^{17}$, que o exercício da cidadania implica em exercício de garantias jurídicas e políticas fundamentais, importando em deveres jurídicos e políticos, onde a sociedade faz parte. Sendo que o fortalecimento da cidadania vem a implicar na implementação de políticas públicas que promovam o seu pleno exercício.

Por conseguinte, todos aqueles que possuem o status de cidadão são iguais. E o racismo e os reflexos na desigualdade, mesmo que com melhorias nos indicadores, como de informalidade, desemprego, redução da pobreza e o desenvolvimento de ações afirmativas, conquistam um debate amplo sobre o tema racial, que vem a proporcionar novo patamar de condições de vida da população negra no Brasil.

Observa-se que mesmo com algumas melhorias verificadas nos grupos sociais, persiste ainda a desigualdade intensa, quando se comparam os indicadores sociais de brancos e negros. O peso do racismo, bem como a sua intervenção na conformação de pontos de início, tratamento social diferenciado e acesso desigual é evidenciado na administração pública, mesmo que considerados critérios impessoais na seleção de cargos efetivos.

Justifica-se porque, de acordo com o IPEA, que da mesma forma ocorre no ingresso à universidade, a despeito dos critérios mais neutros de seleção, resta comprovado que não se tem condições iguais de formação e preparação dos candidatos, além de se constatarem os níveis de condições de vida precários e também vivenciados pela população negra.

A segunda tabela apresenta a distribuição dos ocupados, por cor ou raça, sendo que a representação da população negra é maior em ocupações formais, tendo mais intensidade no funcionalismo público. A diferença é maior ainda no setor público federal, onde as condições de trabalho, remuneração entre outros são ainda mais diferenciados que os demais níveis. Nota-se que a lei $\mathrm{n}^{0} 12.990$ de 2014 somente trabalha com o setor público federal, não de Estados e municípios.

\footnotetext{
${ }^{16}$ LISZT, Vieira. Os argonautas da cidadania: a sociedade civil na globalização. Rio de Janeiro: Record, 2001, p. 102.

${ }^{17}$ DA COSTA, Marli Marlene Moraes; REIS, Suzéte da Silva. Espaço local, cidadania e inclusão social: perspectivas a partir das políticas públicas educacionais. Revista Brasileira de Direito, Passo Fundo, v. 7, n. 2, p. 104-126, out. 2011.
} 
Tabela 2. Distribuição dos ocupados por cor ou raça no ano de 2012

\begin{tabular}{l|c|c}
\hline Ocupação & Brancos \% & Negros \% \\
\hline População economicamente ativa & 47,0 & 52,2 \\
População ocupada & 475 & 51,7 \\
Empregados com carteira & 51,6 & 47,6 \\
Funcionários públicos e militares & 53,8 & 45,3 \\
Funcionários públicos e militares no setor federal & 85,3 & 40,3 \\
& & \\
Ocupados no setor público & 51,5 & 47,4 \\
Funcionários públicos / militares & 53,8 & 45,3 \\
Empregados - setor público & 48,8 & 50,9 \\
Ocupados no setor público federal & 58,6 & 39,9 \\
Ocupados no setor público estadual & 54,0 & 44,4 \\
Ocupados no setor público municipal & 48,0 & 51,4 \\
\hline
\end{tabular}

Fonte: Instituto Brasileiro de Geografia e Estatística / Pesquisa Nacional por Amostra de Domicílios

Entre os ocupados no setor público federal, aquele funcionário público e militar é o mais frequente da população branca, $60 \%$. Na população negra encontram-se dos 30\% restantes, 58\% desses 30\% são homens negros e 7,5\% mulheres negras. Ainda, um quarto dos homens brancos está alocado no nível federal, sendo que este apresenta a maior remuneração. Outra objeção é a inclusão desse critério social para os concursos públicos. O IBGE analisa a frequência no ensino superior, de acordo com o nível de renda, e verifica que da população negra que cursa a graduação, apenas 3\% têm renda menor que um quarto de salário mínimo.

Considerando a renda de até um salário mínio, estão 30\% dos negros que frequentam a graduação. Aqueles que têm até dois salários mínimos representam menos de um quarto de todos os indivíduos que cursam o ensino superior. Quando se trata de pós-graduação (nível de mestrado e doutorado), a participação se mostra ainda mais reduzida, $28,7 \%$ dos estudantes são negros. Contudo, os que possuem renda de até dois salários mínimos representam 10,2\% de todos os estudantes, brancos e negros.

Para análise do ensino dos negros no Brasil, tomam-se os dados de 2015, apresentados pelo IBGE, é necessária essa verificação, pois parte da justificativa da 
lei está no ensino desigual entre brancos e negros, bem como na sua condição financeira, de poder se manter no estudo.

Tabela 3. Estudantes de 18 a 24 anos de idade, total e respectiva distribuição percentual, por nível de ensino frequentado e cor ou raça, com indicação do coeficiente de variação

Estudantes de 18 a 24 anos de idade (1)

\begin{tabular}{|c|c|c|c|c|c|c|c|c|c|}
\hline \multirow{3}{*}{$\begin{array}{c}\text { Total } \\
\text { (1000 } \\
\text { pessoas) }\end{array}$} & \multirow{3}{*}{$\begin{array}{l}\text { CV } \\
(\%)\end{array}$} & \multicolumn{8}{|c|}{ Distribuição percentual, por nível de ensino frequentado (\%) } \\
\hline & & \multicolumn{2}{|c|}{ Fundamental } & \multicolumn{2}{|l|}{ Médio } & \multicolumn{2}{|c|}{ Superior (2) } & \multicolumn{2}{|c|}{ Outros (3) } \\
\hline & & Percentual & $\begin{array}{l}\text { CV } \\
\text { (\%) }\end{array}$ & Percentual & $\begin{array}{l}\text { CV } \\
\text { (\%) }\end{array}$ & Percentual & $\begin{array}{l}\text { CV } \\
\text { (\%) }\end{array}$ & Percentual & $\begin{array}{l}\mathrm{CV} \\
\text { (\%) }\end{array}$ \\
\hline 3337 & 1,8 & 2,2 & 9,4 & 21,5 & 2,9 & 70,9 & 1,0 & 5,4 & 6,2 \\
\hline 3467 & 1,5 & 6,2 & 5,8 & 39,5 & 1,8 & 46,8 & 1,6 & 7,5 & 5,0 \\
\hline
\end{tabular}

Fonte: Instituto Brasileiro de Geografia e Estatística

Dessa análise, foram consideradas as desigualdades sociais no setor público e na educação, base de acesso a qualquer mercado de trabalho. Observa-se a partir disso que a reserva das vagas não vem a eximir os negros na sua conquista de aprovação nas fases que os concursos disponibilizam. Apenas aqueles ora habilitados no certame e considerados aptos para o cargo escolhido, poderão se beneficiar da reserva das vagas.

Por conseguinte, o estudo da história brasileira não permite outra conclusão, a não ser aquela que os negros foram relegados a um objeto durante todo o desenvolvimento do Brasil, e quando adveio o fim da escravidão, não lhes foi concedido apoio por parte do Estado, com a finalidade de compensação da discriminação racial. E a partir disso resulta até os dias atuais, a ideia de que os negros ainda ocupam uma posição menos desfavorecida economicamente, com níveis de analfabetismo e marginalização do mercado de trabalho ${ }^{18}$. A corrente favorável a essa ação afirmativa aponta que a Constituição Federal prevê que todos são iguais perante a lei.

É certo que a população negra não vive em condições de igualdade plena com relação aos brancos, e o fruto dessas condições desumanas são aquelas situações em que foram submetidos durante a escravidão. A partir disso, considera essa corrente que o artigo $3^{\circ}$ da Constituição Federal preconiza que o Estado não pode

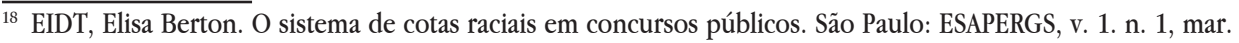
2015. 
assistir de forma passiva a privação em que se encontram a população negra, sob pena de a discriminação se perpetuar. Não se torna suficiente a repreensão das práticas de discriminação, com a finalidade de igualar os indivíduos, mas é necessária a eliminação das desigualdades por meio de medidas compensatórias, é o que dispõe Flavia Piovesan.

Faz-se necessário combinar a proibição da discriminação com políticas compensatórias que acelerem a igualdade enquanto como processo. Isto é, para assegurar a igualdade não basta apenas proibir a discriminação, mediante legislação repressiva. São essenciais as estratégias promocionais capazes de estimular a inserção e inclusão de grupos socialmente vulneráveis nos espaços sociais. Com efeito, a igualdade e a discriminação pairam sob o binômio inclusão/exclusão. Enquanto a igualdade pressupõe formas de inclusão social, a discriminação implica violenta exclusão e intolerância à diferença e à diversidade. O que se percebe é que a proibição da exclusão, em si mesma, não resulta automaticamente na inclusão. Logo, não é suficiente proibir a exclusão, quando o que se pretende é garantir a igualdade de fato, com a efetiva inclusão social de grupos que sofreram e sofrem um consistente padrão de violência e discriminação ${ }^{19}$.

As ações afirmativas, que se incluem no estabelecimento das cotas, colocam em prática a igualdade material, em que o tratamento desigual conferido aos negos com as cotas busca impedir a compensação de uma desigualdade social impregnada na história brasileira. As discriminações são recebidas como compatíveis à igualdade, e apenas tem vínculo de correlação lógica entre a desigualdade de tratamento e a peculiaridade diferencial, desde que essa correlação seja incompatível com os interesses constitucionais, Piovesan (2005). A concepção da utilização das cotas é um meio, uma medida transitória, possibilitando a visibilidade do povo negro.

A corrente que se mostra contrária à cota baseia-se em diversos argumentos, assim como a corrente favorável, e um deles se relaciona com o pressuposto de que a solução para as distorções raciais é a melhoria da educação, do ensino fundamental e médio. Os defensores do programa de cotas são contrários a isso. Entendendo-se que as cotas são uma alternativa emergente e provisória, contrariamente a melhoria da rede pública, que exige esforço de longo ou médio prazo, com o ciclo de uma geração, no mínimo ${ }^{20}$.

As perguntas que estes mais fazem é "não existem brancos marginalizados e

\footnotetext{
${ }_{19}$ PIOVESAN, Flavia. Ações afirmativas da perspectiva dos direitos humanos. Cadernos de Pesquisa, São Paulo, v. 35, n. 124, jan. 2005. p. 43.

${ }^{20}$ DOMINGUES, Petrônio. Ações afirmativas: a saída conjuntural para os negros na educação. In: PORTO, Maria do Rosário Silveira et al. (Org.). Negro, educação e multiculturalismo. São Paulo: Panorama, 2002.
} 
pobres? " Ou "porque somente a classe negra possui um tratamento diferenciado"; "a política das cotas não deveria observar a classe social e não a cor?", e "o negro que tem uma classe social melhor, pode se prevalecer da sua cor para o ingresso nesse sistema? ". Trata-se de questionamentos apresentados por Elisa Berton Eidt ${ }^{21}$, que não possuem respostas exatas. Ainda se tem a questão da constatação, ou averiguação da autodeclaração feita. A primeira experiência é das universidades, e agora estendidas aos concursos, leva a consideração de que esta é a melhor maneira de realizar a aferição dos destinatários das cotas.

Mas ainda há certo questionamento, na medida em que se obriga as pessoas a se autodeclararem negras ou não negras, não podem existir fraudes? E no caso de pessoas que são aparentemente claras e utilizam esse sistema? São exceções apresentadas por essa corrente. Mesmo assim, não vem a constituir uma fraude, até porque os critérios de definição de pessoa negra não são os marcadores biológicos, provando a genética de que raça não existe, e o critério utilizado é o político e ideológico. Ou seja, negro é o que se assume, identifica-se, todo aquele que abraça uma luta contra o racismo.

As políticas que passam a estabelecer as cotas raciais devem respeito ao percentual de negros no total do Brasil, devendo ser sempre proporcional, correspondendo à realidade local; se tem uma tradição de pensar que os programas vêm para beneficiar, de forma igual, todas as pessoas, independentemente da sua cor, mas as pesquisas demonstram que isso é um engodo. Ou seja, as políticas sociais, de maneira isolada, não atacam o racismo. Dessa maneira, afirma-se a cidadania por meio da lei de cotas em concursos públicos, pois além de ser um instrumento promotor da cidadania, e mesmo que se pense que esta é uma forma de discriminação reversa, ao fundo consistem no exercício da cidadania, quando da união de forças críticas para que os direitos sejam garantidos e viabilizados. Passa-se agora às conclusões finais, para responder a problemática da pesquisa.

\section{CONCLUSÃO}

De todo o exposto, com a compreensão da ação afirmativa, e a partir dela a observação da justificativa do projeto de lei que deu origem à lei no 12.990 de 2014, e a decisão de constitucionalidade proferida pelo STF, buscou-se responder, por

${ }^{21}$ EIDT, Elisa Berton. O sistema de cotas raciais em concursos públicos. São Paulo: ESAPERGS, v. 1. n. 1, mar. 2015. 
meio desta análise, assim como com os dados obtidos no PNAD e IBGE, se com a lei de reserva de vagas para negros em concursos públicos estará se afirmando a cidadania ou recaindo-se em uma discriminação reversa? Preliminarmente tem-se que, de acordo com a história, a cidadania vem sendo compreendida como o exercício dos direitos civis que, de certa forma, é também a história dos direitos humanos e das lutas de afirmação daqueles valores éticos, como a liberdade, dignidade, igualdade, democracia e justiça.

Considerando isso, o movimento negro, as organizações, entre outras, verificam-se no Brasil que mesmo com nossas próprias características, tem-se a ação afirmativa como promotora da cidadania. Ou seja, isso se deve à luta pela eficácia dos direitos, à fomentação de positivação daqueles ainda não concebidos. Quando se trata da ação afirmativa como uma luta dos marginalizados, que decorrem da discriminação racial está se servindo a ação afirmativa como uma forma de construção da cidadania. Entendendo-se que a união dos indivíduos, na defesa dos seus direitos, já dá conta do efetivo exercício cidadão.

Pode-se ainda observar a ação afirmativa também como um instrumento de discriminação reversa, quando se traduz a ação como mero sistema de cotas, gerando uma celeuma ainda maior, tendo em vista os posicionamentos contrários à ideia de destinação de percentual de vagas para negros. Aqui está a discussão de estar se impondo por meio da ação, uma discriminação reversa, ou seja, o branco acaba sendo preterido em condições de igualdade com a população negra, por meio das políticas estatais.

Deve-se desmistificar a ideia de inteira benesse à população negra por meio da reserva de vagas em concursos públicos federais, pois estes só acessam estas vagas, se detiver pontuação inferior à aba de "ampla concorrência", ou seja, o negro que pontuar da mesma forma que outro candidato da "ampla concorrência", não utilizará da reserva das vagas. Além do mais, deve passar por todas as etapas que o concurso público predispor, sem atropelamentos a outros candidatos. Isso se justifica em virtude da baixa taxa de escolarização, apresentada pelo IBGE.

Daí a discussão de se estar impondo com a ação afirmativa uma discriminação reversa, ou seja, o branco acaba sendo preterido em condições de igualdade com o negro por meio de políticas notadamente estatais. Conclui-se que a cidadania, por meio da lei de cotas em concursos públicos, além de ser o seu instrumento de promoção, e mesmo que uma parte da sociedade pense que esta é uma forma de dis- 
criminação reversa, ao fundo consiste em seu exercício, quando da união de forças críticas para que os direitos sejam garantidos e viabilizados.

\section{REFERÊNCIAS}

BEDIN, Gilmar Antônio. Cidadania, direitos humanos e equidade. Ijuí: Unijuí, 2012.

BRASIL. Constituição (1988). Constituição da República Federativa do Brasil. Brasília, DF: Senado Federal, 1988.

BRASIL. Lei Ordinária n. 12.990, de 09 de junho de 2014. Reserva aos negros 20\% (vinte por cento) das vagas oferecidas nos concursos públicos federais. Diário Oficial da República Federativa do Brasil, Brasília, DF, 2014. Disponível em: < http:// www.planalto.gov.br/ccivil_03/_Ato2011-2014/2014/Lei/L12990.htm > . Acesso em: 02 de jun. 2017.

CARVALHO, José Murilo de. Cidadania no Brasil: o longo caminho. Rio de Janeiro: Civilização brasileira, 2016.

COSTA, Marli Marlene Moraes da; REIS, Suzéte da Silva. Espaço local, cidadania e inclusão social: perspectivas a partir das políticas públicas educacionais. Revista Brasileira de Direito, Passo Fundo, v. 7, n. 2, p. 104-126, out. 2011.

DOMINGUES, Petrônio. Ações afirmativas: a saída conjuntural para os negros na educação. In: PORTO, Maria do Rosário Silveira et al. (Org.). Negro, educação e multiculturalismo. São Paulo: Panorama, 2002.

EIDT, Elisa Berton. O sistema de cotas raciais em concursos públicos. São Paulo: ESAPERGS, v. 1. n. 1, mar. 2015.

IBGE. Instituto Brasileiro de Geografia e Estatística. 2012. Disponível em: < http://www.ibge.gov.br/home/> . Acesso em: 10 de jul. 2017.

IPEA. Instituto de Pesquisa Econômica Aplicada. 2005. Disponível em: < http:// www.ipea.gov.br/portal/> . Acesso em 05 de jul. 2017. 
GOMES, Joaquim Barbosa. Ação afirmativa e princípio constitucional da igualdade: o direito como instrumento de transformação social. Rio de Janeiro: Renovar, 2001.

LISZT, Vieira. Os argonautas da cidadania: a sociedade civil na globalização. Rio de Janeiro: Record, 2001.

MARSHALL, Thomas Humphrey. Cidadania, classe social e status. Rio de Janeiro: Zahar, 1967.

PIOVESAN, Flavia. Ações afirmativas da perspectiva dos direitos humanos. Cadernos de Pesquisa, São Paulo, v. 35, n. 124, jan. 2005.

PNAD. Pesquisa Nacional por Amostra de Domicílios. 2012. Disponível em: < http://www.ibge.gov.br/home/estatistica/pesquisas/pesquisa_resultados.php?id_ pesquisa $=40>$. Acesso em: 05 de jul. 2017

ROCHA, Cármen Lúcia Antunes. Ação afirmativa: o conteúdo democrático do princípio da igualdade jurídica. São Paulo: Revista Trimestral de Direito Público, v. 15 n. 85, mar. 1996.

RODRIGUES, Fernando. Racismo cordial. In. TURRA, C.; VENTURI, G. (Org.). Racismo cordial: a mais completa análise sobre preconceito de cor no Brasil. São Paulo: Folha de São Paulo / Datafolha, 1998.

SCHMIDT, João Pedro. O caráter público não-estatal da universidade comunitária: aspectos conceituais e jurídicos. Revista do Direito, Santa Cruz do Sul, p. 44-66, jan. 2008.

SEN, Amartya. Desenvolvimento como liberdade. São Paulo: Cia das Letras, 2000.

SEPPIR. Secretaria de Políticas de Promoção da Igualdade Racial. 2013. Disponível em: < http://www.seppir.gov.br/> Acesso em: 06 de jul. 2017. 